\title{
Assembly Building Material Management Method Based on BIM Technology
}

Xinhua Wu ( $\sim$ skd992813@sdust.edu.cn )

Shandong University of Science and Technology

Research

Keywords: BIM Technology, Prefabricated Building, Material Management, Inventory Turnover Times

Posted Date: September 8th, 2020

DOI: https://doi.org/10.21203/rs.3.rs-72285/v1

License: (c) (i) This work is licensed under a Creative Commons Attribution 4.0 International License. Read Full License 


\title{
Assembly Building Material Management Method Based on
}

\author{
BIM Technology \\ Xinhua $\mathbf{W u}^{*}$ \\ College of Resources, Shandong University of Science and Technology, Taian 271019, Shandong, China \\ skd992813@sdust.edu.cn \\ [*Corresponding author]
}

\begin{abstract}
The primary goal of material management is to reasonably arrange the use of materials, which is particularly important for the construction industry. In the process of material management, on the premise of meeting the requirements of production and construction materials, try not to increase additional invent ory and reduce the amount of capital. In order to explore the method of prefabricated building material management, this paper uses the method of sampling survey and sand table simulation technology to compare the prefabricated building material management based on BIM Technology with the conventional method. We make a comparative study on the procurement, warehouse and material quality of materials, mainly focusing on the production stage and construction stage of the building, and analyze the difference of material management between the two technical methods in different stages. Through experiments, we find that the average inventory turnover times of the BIM based prefabricated building materials management method is 6 , and that of the conventional method is 4 , but in the construction stage, the gap between the two is narrowed. The turnover times of the prefabricated building material management method based on BIM Technology is reduced to 3 , and that of the conventional method is reduced to 2 . It can be seen that the prefabricated building material management based on BIM Technology can reduce the capital use and warehouse occupancy rate more than the conventional method, and at the same time, the quality control of materials is also better.
\end{abstract}

Keywords: BIM Technology, Prefabricated Building, Material Management, Inventory Turnover Times

\section{Introduction}

China's urban and rural construction area is about 2 billion $\mathrm{m} 2$ each year, which is the largest construction market in the world. However, there are a series of problems in China's construction industry, such as large energy consumption, poor quality, long cycle, high cost and non-environmental protection, so it is urgent to take modern measures to promote the transformation and upgrading of the construction industry. With the help of BIM Technology, we can avoid the construction problems of prefabricated buildings, such as "mistakes, omissions, collisions and shortages", realize the integrated collaborative management from design to operation and maintenance of prefabricated buildings, and effectively improve the overall construction and management level of prefabricated buildings. There are still many difficulties in the application of BIM Technology in prefabricated building, such as imperfect technical standards and low industry recognition. To achieve the seamless combination of BIM Technology and prefabricated building, it needs to be further improved in practice.

Prefabricated structure is a hot topic in current architectural research. Wang summarized the advantages and disadvantages of prefabricated building, pointed out the problems exposed 
in the management of prefabricated building, introduced BIM Technology into the whole life cycle management of prefabricated building, and specifically elaborated the application of BIM Technology in the whole life cycle management of prefabricated building. Through the combination of specific cases, he analyzed its application in various stages. BIM Technology in the whole life cycle of prefabricated component construction management, from design, production, construction to operation and maintenance, has broad application prospects, but his research lacks certain data support, and the result is not accurate enough [1]. Based on the characteristics and shortcomings of prefabricated buildings in China, Yan constructed the integrated management mode of prefabricated building projects by combining BIM Technology and integrated management theory. Then, from the perspective of goal integration, organization integration and process integration, this paper analyzes the construction principles of assembly building project integrated management mode, and discusses the operation process, information integration and information interaction of assembly building project integrated management mode from the perspective of information classification, and then puts forward suggestions on the application of BIM integrated management process of prefabricated building. His theory is conducive to promote the integration and optimization of construction enterprise resources and promote the development of the whole industry [2]. In order to improve the design level and design efficiency of domestic fashion designers, and solve the severe challenges faced by the management and use of advanced information technology tool BIM Technology in domestic fashion design, Zhang Lin, from the perspective of strategic development, established a set of home decoration design system based on BIM Technology, carried out unified three-dimensional home decoration design, unified price management, and A complete enterprise knowledge management foundation is established, and the domestic clothing design quantity management system is calculated from the design drawings. The application of BIM Technology in home decoration industry is helpful to promote the development of scale economy of domestic garment enterprises, especially to improve the competitiveness of enterprises in the field of home decoration design tools. His theory is that under the implementation of the design system based on BIM Technology in home decoration Design Company, the problem of single design tool and centralized management of enterprise resources in traditional decoration design industry is solved. The 3D decoration design based on BIM Technology tool is realized, and the design resources are managed uniformly, which has accumulated into an intangible asset of a clothing enterprise for a long time, and improves the efficiency of domestic fashion design Rate and the competitiveness of decoration enterprises. However, his research lacks a certain practical basis and cannot see its advantages and disadvantages from the most essential point of view of society, so it is not very convincing [3]. BIM Technology has changed the way people acquire and transmit information in traditional projects, according to the classification of building intelligence alliance of America, there are 25 listed persons in the application of Bim in construction engineering. Analyzing all participants of construction projects, including architectural planners, owners, contractors, property management companies and construction supervision companies, the construction supervision company is the most suitable organization technology to promote BIM. In addition, Shi also proposed the establishment of BIM Technology consulting, expanding the business coverage of the existing supervision company, BIM consulting, including the supervision business into BIM consulting, and combining the supervision company with BIM consulting. Which to a large extent belongs to the innovation of traditional technology, conforms to the 
development of the times and the trend of social development [4].

In this paper, sand table simulation is used to carry out the prefabricated building experiment, and the material management method based on BIM Technology is compared with the conventional method. Through the comparison of the two construction methods, the most suitable logistics management mode and the most suitable construction method for prefabricated building are found.

\subsection{BIM Technology}

\section{BIM Technology and Prefabricated Building Material Management}

BIM Technology, namely building information model, is a new type of information technology. The carrier of this technology is building model, which can collect and process various information and real data of construction projects, and guide the construction and design management of related construction projects with the application of informatization. This technology is mainly used in engineering design and management, integrating the relevant information of each project in the parameter model, sharing and transferring the project operation, maintenance and planning process, so that the technical personnel can correctly understand all kinds of building information and make efficient response measures. It plays an extremely important role in saving costs, shortening construction period and improving production efficiency [5-6].

(1) Features of BIM

1) Visualization, in the construction industry, the characteristics of visualization play a very important role in the application of the construction industry. For example, in the construction drawing, the information expression of each component in the drawing is simply drawn on the drawing with lines, and the real structural form of this drawing needs professional personnel to explore [7]. For the simple and easy to understand things, this kind of imagination is feasible. However, with the diversification of architectural forms in the construction industry in recent years, and the continuous introduction of complex modeling, it makes the things that only rely on human brain to imagine become a little inadequate. Therefore, under the visualization of BIM technology, the traditional obsolete line type components are transformed into three-dimensional physical graphics to display. In the construction industry, there are also design renderings, but such renderings are usually produced by professional production teams under the bar information, not by the information of components. There is a lack of feedback and interaction between the same components. The visualization in BIM has a strong feedback and interaction between the same components, each process in BIM building information model is visualized. This result can not only be used to show the effect and generate reports, but also, most importantly, the discussion, decision-making and communication of project operation, design and construction process are carried out in such a state, which will be more transparent and clear [8-9].

2) Coordination, both the design and owner units and the construction units are doing coordination and coordination work, which is the key content in the construction industry. However, when the project encounters implementation problems, it is necessary to organize relevant personnel to hold a coordination meeting to find out the causes of the construction problems and find solutions, and then make corresponding remedial measures for the construction changes [10]. However, the coordinated solution has a certain lag. In the design of 
the project, the communication between the designers may not be very smooth, so there are various knowledge collision problems. For example, in the piping layout of HVAC and other specialties, because the construction drawings are different, in the real construction, there may be conflicts between the beam of structural design and the pipeline layout, this kind of problem is often encountered in daily construction, but it can only be handled after the problem appears. The coordination of BIM Technology can solve this problem well, that is, BIM building information model can coordinate the collision problems of various disciplines in the early stage, generate and provide coordination data. The coordination function of BIM Technology is not only the collision between different disciplines, but also plays a great role in promoting the layout of elevator shaft, fire compartment and underground drainage layout.

3) Simulation, the simulation of BIM Technology refers to the simulation of things that cannot be operated in the real world. In the design stage of BIM, it can also carry out simulation experiments on some design things, such as emergency evacuation simulation, energy saving simulation, heat conduction simulation, sunshine simulation, etc. Moreover, 4D simulation in the construction and bidding stage, that is, the actual construction is simulated by the construction organization design, so as to find the most suitable construction scheme for construction more clearly. At the same time, the 5D simulation experiment (based on the cost control of 3D model) will better control the cost, and the handling mode of daily emergency can be simulated in the operation stage, For example, fire personnel evacuation or earthquake escape simulation [11].

(2) Application of BIM

1) BIM Technology is applied to the architectural design stage. The technology is based on 3D modeling, and the information database is established by parametric design. The presentation form is mainly database. There are three stages in the establishment of BIM model, including standard formulation, model establishment and model application [12-13]. Each graphic unit in the model has parameters such as size, type, material and so on. The parameters control all component models, which helps to realize the relevance of BIM model. When a parameter in a component changes, other components related to it will be updated accordingly, and the omissions, errors and even information inconsistency between drawings will be solved. Collaborative management and information technology is the greatest value of BIM Technology. The design models of various disciplines are integrated on the same platform, which makes the collaborative effect between the participants and the disciplines possible.

2) Cost management and engineering quantity statistics, in the traditional era, cost personnel have to spend a lot of energy and time in the statistical engineering quantity, but the cost accuracy is not very high. On the contrary, in BIM Technology, because it is a database with a large amount of building information, the engineering quantity can be quickly calculated and counted by computer in the database, this eliminates the calculation error caused by manual operation [14]. The combination of Bim and Internet of things technology can ensure the quality of components, and it is more convenient to manage the transportation, construction, production and storage, operation and maintenance process of components, and also meet the needs of users.

3) BIM is used in the operation and maintenance stage. With the more and more extensive use of the Internet of things, BIM Technology also ushers in new challenges in the operation and maintenance stage of prefabricated buildings. For example, in case of a sudden fire, BIM Technology will automatically judge and trigger the alarm through the model interface, accurately 
locate the fire location and timely handle the disaster and evacuate the crowd. In terms of BIM Technology in equipment maintenance and prefabricated buildings, the operation and maintenance personnel can obtain the information of component quality through the use of RFID tags, as well as the relevant information of transporters, installation workers, construction workers and production workers, so as to quickly trace the responsibility of prefabricated construction quality. BIM Technology can also use embedded RFID tags to effectively monitor, analyze and detect the use process of the whole prefabricated building, so as to accurately locate the high energy consumption parts and find the best treatment method.

\subsection{Prefabricated Buildings}

(1) Definition of prefabricated building

Prefabricated building is considered as a kind of green building. In fact, most of its use is promoted by sustainable technology. It is a new architectural concept under the development of science and technology [15]. Compared with the traditional building type, this building type greatly reduces the net weight of the building and improves the efficiency in construction. Its core purpose is to use the optimal design scheme to carry out the construction and assembly of building components in the shortest time, but correspondingly, In order to achieve the overall quality requirements, in the actual construction process, the building type must ensure that each building assembly component has a good running state, only in this way can the safety and quality of prefabricated buildings be ensured [16-17].

(2) The core of prefabricated building

Prefabricated building is just like building block building. This kind of building is to assemble the beams, floors, columns, walls and other components on the assembly line on site to build a house, which realizes the factory manufacturing, construction assembly, function modernization and design diversification. This is the "three modernizations" (industrialization, informatization, standardization) method to manage, build and use buildings, which makes the construction industry change from traditional to modern ways of science and technology, saving, environmental protection, intensive, green and so on [18]. "Integration" is the core of prefabricated building, while the main line of "integration" is informatization. Through the role of BIM Technology on prefabricated building, it can effectively control and manage the life cycle of prefabricated building, deepen the design of components, optimize the design scheme, and operate and maintain the assembly simulation building in the production, transportation and use of components, Improve the efficiency of assembly building production, construction and design, realize the industrialization of building flute, and promote the promotion of prefabricated building.

(3) Influencing factors of prefabricated building

1) Due to process factors, in the manufacturing and production of prefabricated buildings, problems such as slurry leakage and dislocation often occur due to unreasonable splicing of formwork. Therefore, it is necessary to clarify the specific parameters and installation position of the formwork before pouring concrete to ensure that the bolts meet the tightness of relevant standards. If the formwork bolts are not fixed properly, the formwork bolts shall be fixed, Then there are concrete vibration compaction cannot meet the requirements, which leads to the emergence of a large number of cracks in the concrete watering maintenance [19]. In addition, if the thickness of the interlayer is not strictly controlled, it will increase the thickness of the mortar 
layer, cause obvious changes in the position of the concrete, or cause the slurry layer to become thinner, so that a lot of air enters into the joint surface, and the setting out is not accurate, resulting in different elevations.

2) Material factor, in the construction of prefabricated buildings, the components used must be made. If the components do not meet certain standards or are put into use without inspection, it is difficult to guarantee the performance of prefabricated buildings. In addition, there are many aspects that affect its performance, so we must pay enough attention to them. If there is no special personnel to do special inspection on performance and quality before construction, it is not clear whether the quality of materials meets the construction requirements.

3) Personnel and construction machinery factors, if the personnel and construction machinery can be reasonably controlled, then the quality of construction will be guaranteed in essence. Therefore, the construction unit should strictly manage and control the construction personnel and construction machinery. Different from the original building form, the configuration of construction machinery and prefabricated construction personnel will change obviously, so the person in charge should manage the construction according to the actual situation, so as to ensure the significant improvement of quality. Different machinery and hoisting equipment should be used in strict accordance with relevant requirements, so as to give full play to the performance advantages of these machines [20].

4) Management factors: at present, construction enterprises need to pay more attention to the management work, and the management method adopted is fine. At the same time, in the actual construction process, the management personnel must combine with the actual situation to improve and formulate the management plan, and flexibly adjust the management strategy under the operation conditions, so as to ensure the effective improvement of the management level and meet the site construction [21]. However, after the in-depth analysis of prefabricated construction, it will be found that the quality of management personnel needs to be improved. Otherwise, innovative ideas cannot be applied in management, which will lead to the failure of management to play its real value and role. Moreover, without sound management system and perfect construction rules, it cannot provide accurate basis for management work.

\subsection{Material Management}

Material management is the general name of a series of organization, control, planning and other management activities for the acceptance, supply, purchase, rational use, distribution, storage, comprehensive utilization and saving of various materials required by enterprises in production and operation activities [22-23]. It can not only coordinate the relationship between the functional departments within the enterprise, but also control the materials from the overall perspective of the enterprise, so as to achieve the economic benefits of fast turnover, low consumption, good supply and low cost, so as to ensure the smooth production of the enterprise. There are four basic activities in material management: first, forecasting the amount of materials used to make material supply plan; second, purchasing, organizing the source of goods or adjusting materials; third, the storage, acceptance, distribution and collection of materials; fourth, accounting, inventory and statistics of materials[24-25]. With the development of computer technology and manufacturing industry and the flexible use of quantitative analysis methods, the development from simple material reserve management to just in time material management, from manual development to informatization and automation MRP system, from professional 
department management to comprehensive management [26].

In the material management mode, we assume that there are $n$ samples of influencing factors of integrated management, and each sample has $p$ variables. The $n \times p$ matrix is obtained as follows:

$$
\begin{gathered}
X=x_{11}, x_{12}, \cdots, x_{1 p} \\
X=x_{21}, x_{22}, \cdots, x_{2 p} \\
X=x_{n 1}, x_{n 2}, \cdots, x_{n p}
\end{gathered}
$$

Let $\mathrm{X} 1, \mathrm{X} 2, \ldots \mathrm{XP}$ be the original variables and $\mathrm{Q} 1, \mathrm{Q} 2, \ldots, \mathrm{QM}(\mathrm{m} \leq \mathrm{P})$ be new variables, then the linear relationship between them is as follows:

$$
\begin{gathered}
\mathrm{q}_{1}=l_{11} x_{1}+l_{12} x_{2}+\cdots+l_{1 p} x_{p} \\
\mathrm{q}_{m}=l_{m 1} x_{1}+l_{m 2} x_{2}+\cdots+l_{m p} x_{p}
\end{gathered}
$$

Where lij is the load of the original variable on each principal component, and the new variable indexes $q 1, q 2 \ldots$ Are called the first, second,... principal components of the original variable index respectively, and $\mathrm{q} 1$ and $\mathrm{q} 2$ are independent of each other. The essence of principal component analysis is to determine the load $\mathrm{Im}$ of the original variable $\mathrm{x} 1$ on each principal component $q 1$, which are the eigenvectors corresponding to the $m$ larger eigenvalues $\lambda \mathrm{i}$ of the correlation matrix, and standardize the data samples as follows:

$$
X_{i j}=\frac{X_{i j}-\bar{X}_{j}}{S_{j}^{-2}}
$$

Where:

$$
\begin{gathered}
X_{\mathrm{j}}=\frac{1}{n} \sum_{1}^{n} X_{i j} \\
S_{j}=\frac{1}{n-1} \sum_{1}^{n}\left(X_{i j}-\bar{X}_{j}\right)
\end{gathered}
$$

Based on the above calculation, the cumulative variance contribution rate of the first $\mathrm{k}$ factors is calculated as follows:

$$
\mathrm{a}_{k}=\sum_{i=1}^{k} \frac{q S_{i}^{2}}{\lambda_{i p}}
$$

Where $\mathrm{p}$ is the number of factors, and the value of the $\mathrm{i}$-th factor on the $\mathrm{i}$-th sample is expressed as follows:

$$
G_{i j}=a_{k}\left(M_{j 1} X_{1 i}+M_{j 2} X_{2 i}+\cdots+M_{j p} X_{p i}\right)
$$

In formula (7), MJ1, MJ2,... MJP are the factor value coefficients between the $j$ th factor and the $p$-th original variable, and the factor score can be regarded as the weight of each variable, and the sum of MJ1, MJ2,... Mjpde is calculated as follows: 


$$
F_{i}=a_{k}\left(M_{j 1} X_{1}+M_{j 2} X_{2}+\cdots+M_{j p} X_{p}\right)
$$

\section{Experiment Plan and Steps}

\subsection{Subjects}

In this paper, sand table simulation is used to carry out the prefabricated building experiment. The whole process of the implementation of one building is assisted by BIM Technology, and the other building is started at the same time, but without any auxiliary technology, the conventional construction method is adopted. In addition to different technologies, other relevant parameters such as staff and location are selected to compare the gap between the two buildings.

As the ultimate goal of enterprise survival is to maximize the value of the enterprise, profit is the most critical link. Under the condition of a certain price, the minimum cost can maximize the profit. The purpose of material management is to enable enterprises to meet the needs of user departments in an appropriate, timely, appropriate quality and price with the ideal and rapid process and the lowest cost, so as to reduce the loss and maximize the efficiency of materials. The main research direction of this paper is the difference in material management between the two buildings.

\subsection{Experimental Steps}

The building process of prefabricated building can be divided into three stages: design stage, production stage and construction stage. However, in terms of material management, the design phase does not involve material issues, so material management is mainly concentrated in the production stage and construction stage.

The problems involved in material management in production stage and construction stage include supplier selection, product procurement, transportation mode selection, procurement batch and frequency, material quality, warehouse area and raw material scrap rate. In the sand table simulation experiment of this paper, the selection of suppliers is set as the same, but according to the different purchase quantity, the unit price and transportation cost are different. Whether the purchase quantity is appropriate or not is related to the number of inventory turnover. Generally speaking, the higher the inventory turnover times, the more sufficient the utilization of funds, the better the efficiency of inventory management. The lower the scrap rate is, the better the quality of the materials is. The more surplus materials are left after the production or use of raw materials, which indicates that the more cost is wasted.

\subsection{Evaluation Index}

The material management process of construction industry can be roughly divided into three categories: procurement process, warehouse management and material quality monitoring First of all, in terms of purchasing process, the purchasing efficiency and capital occupation can be expressed by the number of inventory turnover, which is equal to the cost of goods sold / average inventory (inventory turnover times = sales cost / average inventory balance). Secondly, in the aspect of warehouse management, the advantages and disadvantages of warehouse management can be evaluated by the occupancy rate of warehouse and the proportion of surplus useless materials in the total purchased materials. At the same time, the quality of 
materials needs to rely on machine or manual detection, and on the other hand, the scrapping situation in the use process should be studied. The scrapping situation can be expressed by the scrap rate of materials.

\section{Analysis of Experimental Results of Material Purchase, Storage and Quality under Different Technical Levels}

\subsection{Procurement Differences between the Two Technologies}

(1) Comparison of inventory turnover times

The number of inventory turnover is the ability to maximize the use of enterprise surplus funds when meeting the daily needs of materials. High inventory turnover times can not only improve the utilization rate of funds, but also reduce the accumulation of materials. Because BIM Technology can make the purchasing personnel know the materials and quantity needed by each production department and construction part in time, the material turnover times of the prefabricated building material management method based on BIM Technology is higher than that of the conventional prefabricated building material management method, and the data is shown in Figure 1.

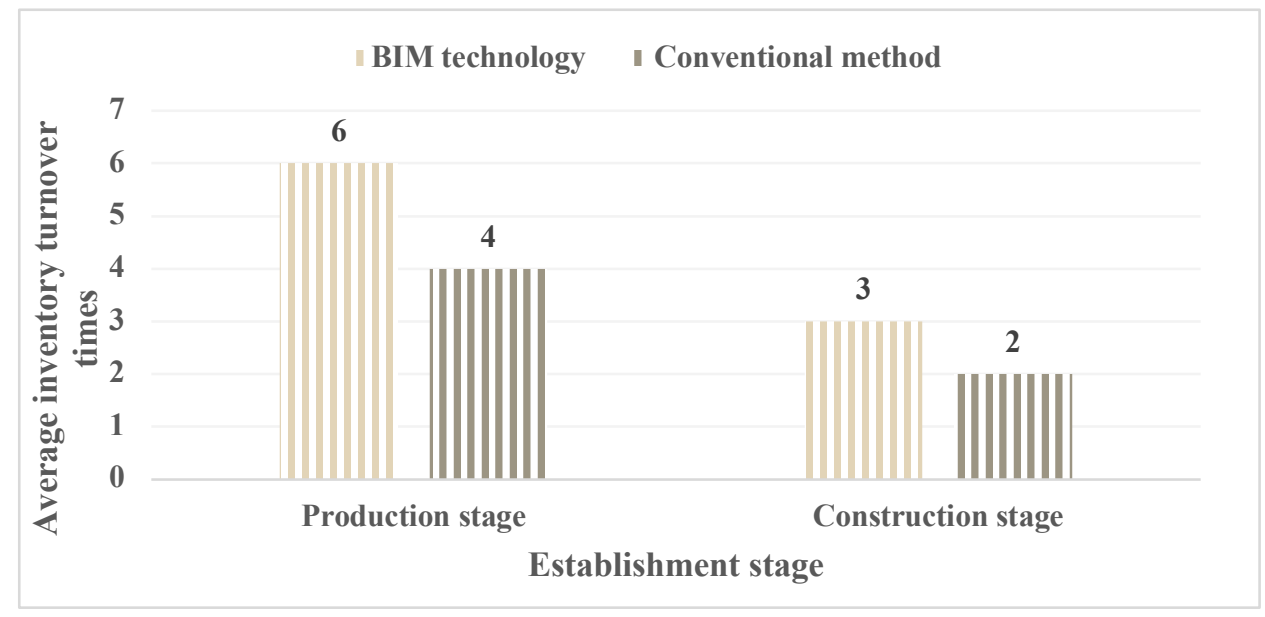

Figure 1. Comparison of inventory turnover times of the two methods

It can be seen from Figure 1 that in the production stage, the average inventory turnover times of the assembly building material management method based on BIM Technology is 6, and that of the conventional method is 4 . However, in the construction stage, the difference between the two methods is narrowed. The turnover times of the assembly building material management method based on BIM Technology is reduced to 3 and the turnover times of the conventional method is reduced to 2 .

(2) Transportation cost comparison

The inventory turnover times of prefabricated building materials management method based on BIM Technology is high, which brings about the problem of rising transportation cost. On the one hand, the transportation times increase, the transportation oil cost and the loss of fixed assets such as materials and vehicles increase. On the other hand, if the quantity of each purchase is large, the cash discount or commercial discount given will increase. Therefore, the conventional method can indirectly reduce the total cost in this respect. The specific transportation cost is shown in Table 1. 
Table 1. Comparison of transportation costs between the two methods in the construction process

\begin{tabular}{|c|c|c|}
\hline & Unit price per purchase & Transportation times \\
\hline BIM technology & 5.32 & 15 \\
\hline Conventional method & 5.11 & 12 \\
\hline
\end{tabular}

As shown in Table 1, the unit price of prefabricated building material management method based on BIM Technology is higher than that of prefabricated building with conventional method. In terms of transportation times, the transportation of prefabricated building material management method based on BIM Technology is three times more than that of traditional method, so the conventional method is better in terms of transportation cost.

\subsection{Storage Differences between the two Technologies}

(1) Warehouse occupancy comparison

The occupancy rate of the warehouse is closely related to the cost. The low occupancy rate of the warehouse can reduce the use of the warehouse and reduce the warehouse rent of the construction project. From the above material turnover times, it can be seen that in the construction process of the prefabricated building material management method based on BIM Technology, the turnover speed of the materials is fast, so the occupancy rate of the warehouse is low. The comparison of the warehouse occupancy rate of the two methods in the construction process is shown in Figure 2.

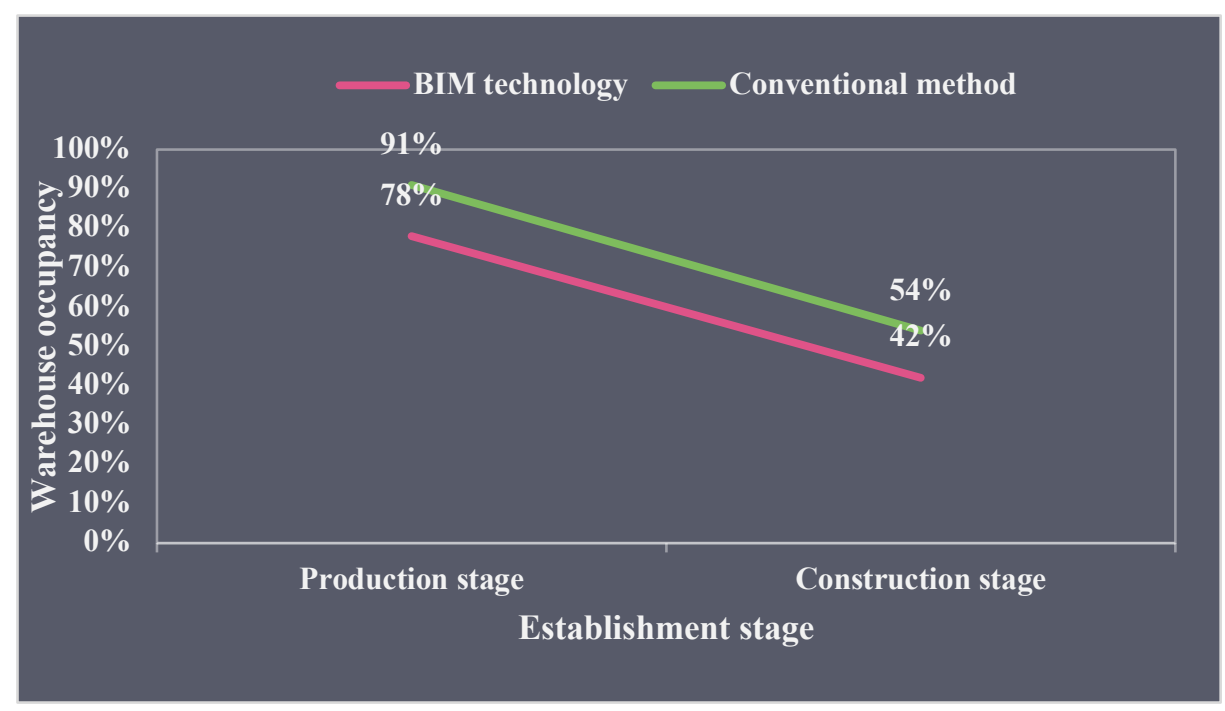

Figure 2 Comparison of warehouse occupancy of two methods in construction process

It can be seen from Figure 2 that the warehouse occupancy rate of the prefabricated building material management method based on BIM Technology is $78 \%$ and $42 \%$ lower than that of the conventional method, no matter in the production stage or the construction stage.

(2) Comparison of the proportion of surplus useless materials in total purchased materials

In the process of construction, surplus materials will inevitably be produced. The more surplus materials, the more the cost. The comparison of the ratio of the surplus useless materials in the total purchased materials of the two methods in the construction process is shown in 
Figure 3.

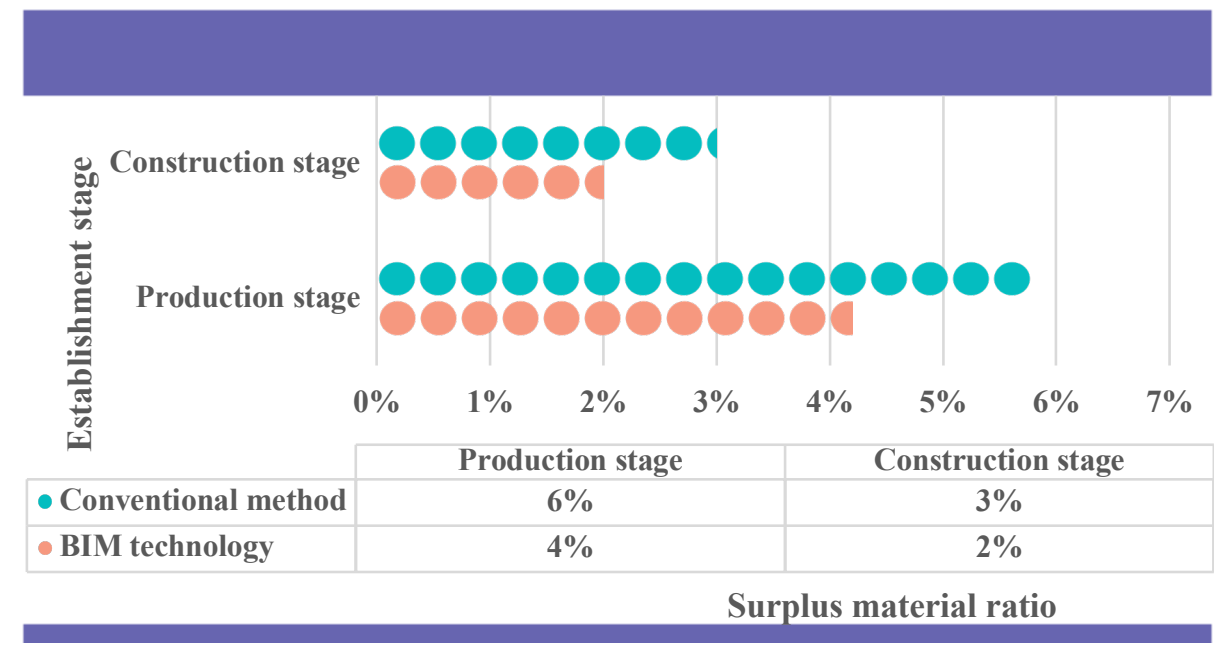

Figure 3 The ratio of surplus useless materials to total purchased materials in the two methods in the construction process

It can be seen from Figure 3 that the proportion of surplus useless materials in the warehouse in the production stage and construction stage of the prefabricated building material management method based on BIM Technology accounts for $6 \%$ and $3 \%$ of the total purchased materials respectively, while that of the conventional method in the production stage and construction stage accounts for $4 \%$ and $2 \%$ respectively.

\subsection{Material Quality Difference}

The quality control of materials is also an important link in material management. We use the method of sampling survey to test the purchased materials of prefabricated buildings under two technical conditions, and calculate the failure rate of all materials. The sampling survey results are shown in Table 2.

Table 2. Results of failure rate in material sampling survey

\begin{tabular}{|c|c|c|c|}
\hline & Sample size & Number of failed & Total failure rate \\
\hline BIM technology & 100 & 2 & $2 \%$ \\
\hline Conventional method & 100 & 5 & $5 \%$ \\
\hline
\end{tabular}

It can be seen from Table 2 that the material failure rate of prefabricated building material management method based on BIM Technology is $2 \%$, and that of conventional method is $5 \%$.

The scrapping of materials in the process of use is also a part of the cost. It is necessary to minimize the occurrence of material scrapping in the material management. The comparison of the two methods of material scrap rate in the construction process is shown in Figure 4

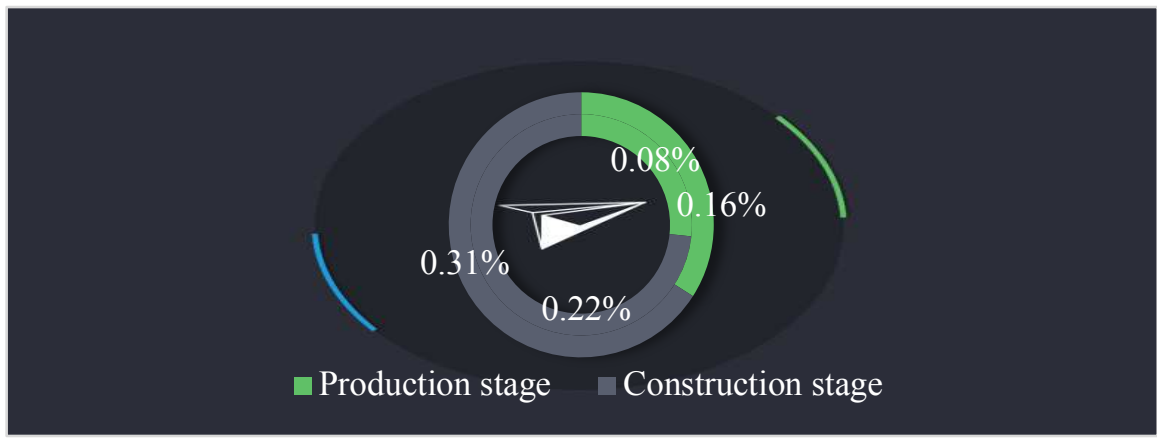

Figure 4 Comparison of material scrap rate of two methods in construction process 
It can be seen from Figure 4 that the material scrap rate in the construction stage is higher than that in the production stage, and the material scrap rate of the fabricated building material management method based on BIM Technology is always lower than that of the conventional method.

\section{Conclusions}

The traditional material management mode mainly relies on the combination of manual scheduling and forklift truck, which requires a large number of manual workers to participate in the operation, and cannot cooperate with each other in information input, equipment operation, inspection and detection. Most of them stay in paper-based operation. In the traditional foundry plant, the process sheet is easy to be polluted or damaged in the process transfer project, resulting in unclear identification. At the same time, it is difficult to input and modify all kinds of processing parameters. The workpiece may not match with the process sheet. All data processing almost depends on manual collection, input, sorting and analysis, which easily causes information delay and distortion. In this paper, sand table simulation is used to carry out the prefabricated building experiment. One of the buildings uses BIM Technology in the whole process of implementation, and the other building does not use any auxiliary technology, but adopts conventional construction methods. Then, the traditional material management and the material management under BIM Technology are compared and studied.

Through the detailed analysis of the two methods, the results show that the proportion of surplus useless materials in the warehouse of BIM Technology in the production stage and construction stage is $6 \%$ and $3 \%$ respectively, while that of the conventional method in the production stage and construction stage is $4 \%$ and $2 \%$ respectively. Therefore, intelligent logistics under BIM is not only accurate in life, but also can save time and effort. However, in the future, the development of intelligent logistics technology still needs a lot of research and technology promotion. The transformation of traditional small workshop factory logistics management mode is imminent. The development of intelligent logistics needs the support of computer system and information flow, it is necessary to design the organization structure, production process and process mode reasonably.

This paper found that the intelligent logistics management system based on BIM Technology compared with traditional logistics management, its response speed is faster, saving time, saving costs, and reducing the error caused by human errors. In addition, based on the BIM construction material dynamic management practice, this paper studies the construction process management of materials, visual statistical analysis of construction materials, Based on the real-time monitoring of supply and demand, the project collaborative management system is established, which provides more intuitive and efficient conditions for the continuous improvement of material management. For the on-site construction management, materials are produced on demand, order delay is avoided, delivery efficiency is improved, visual dynamic management is realized, construction plan is optimized, control of progress and cost is effectively improved, and fine construction management of the project is promoted.

\section{List of Abbreviations}

BIM: Begin of Information Marker

3D: three dimensions

4D: four dimensions 
5D: five dimensions

RFID: radio frequency identification devices

HVAC: High Voltage Alternating Current

MRP: material requirements planning

\section{Declarations}

Consent for publication: Approved.

\section{Competing interests}

There is no potential competitive advantage in our paper. All the authors have reviewed the manuscript and agreed to submit it to your magazine. We confirm that the contents of the manuscript have not been published or submitted for publication elsewhere.

\section{Funding}

This project has no Funding support

\section{Author's contributions}

All authors take part in the discussion of the work described in this paper.

\section{Acknowledgements}

The authors thank the editor and anonymous reviewers for their helpful comments and valuable suggestions.

\section{References}

1) Wang $Q$, Guo $Z$, Mei $T$, et al. Labor crew workspace analysis for prefabricated assemblies' installation: A 4D-BIM-based approach. Engineering Construction \& Architectural Management, 2018, 25(3):00-00.

2) Yan $Y$, Xianzhong $W$. Research and application of BIM technology in the design of prefabricated and assembled concrete structures. Agro Food Industry Hi Tech, 2017, 28(1):542-546.

3) Zhanglin G, Si G, Jun-E L . Application of BIM Technology in Prefabricated Buildings. IOP Conference Series Earth and Environmental ence, 2017, 81(1):012139.

4) Shi Y F , Kang S, Song P P . Research on Development Countermeasures of Prefabricated Building in China Based on SWOT Analysis. Construction Economy, 2016, 12(4):165-172.

5) Li H, Zhao A, Zhang D, et al. Research on building software usage model based on UML model. International Journal of System Assurance Engineering \& Management, 2018, 9(3):1-9.

6) Mostafa S, Kim K P, Tam V W Y, et al. Exploring the status, benefits, barriers and opportunities of using BIM for advancing prefabrication practice. International Journal of Construction Management, 2020, 20(2):146-156.

7) Bortolini R, Formoso C T, Viana D D . Site logistics planning and control for engineer-to-order prefabricated building systems using BIM 4D modeling. Automation in Construction, 2019, 98(FEB.):248-264.

8) Singh M M , Sawhney A, Borrmann A. Integrating rules of modular coordination to improve model authoring in BIM. International Journal of Construction Management, 2019, 19(1):15-31. 
9) Akinade O O, Oyedele L O, Ajayi S O, et al. Designing out construction waste using BIM technology: Stakeholders' expectations for industry deployment. Journal of Cleaner Production, 2018, 180(APR.10):375-385.

10) Lindblad F, Lehman K, Aggerstam E . A comparative study of the environmental impact from transportation of prefabricated building elements using wood or concrete. International Journal of Engineering and Technology, 2019, 11(3):154-161.

11) Li X J . Research on investment risk influence factors of prefabricated building projects. Journal of Civil Engineering and Management, 2020, 26(7):599-613.

12) Bortolini R, Formoso C T , Viana D D . Site logistics planning and control for engineer-to-order prefabricated building systems using BIM 4D modeling. Automation in Construction, 2019, 98(FEB.):248-264.

13) Nan C , Jie Z . Estimation of Environmental Damages of Cement Building and Environmental Benefits of Prefabricated Building: A Case Study Based on a Residential Project in Henan Province, China. Nature Environment and Pollution Technology, 2020, 19(2):721-728.

14) Zou D , Sun C . Analysis for Thermal Performance and Energy-Efficient Technology of Prefabricated Building Walls. International Journal of Heat and Technology, 2020, 38(1):269-273.

15) Sun Y, Liu J , Xia B , et al. Study on Carbon Emission Evaluation of Prefabricated Building at Materialization Stage. Shenyang Jianzhu Daxue Xuebao (Ziran Kexue Ban)/Journal of Shenyang Jianzhu University (Natural Science), 2018, 34(5):881-888.

16) Couto J P , Mendonca P , Reis A P . Prefabricated building systems: Evaluation of the construction practitioners' perception on the environmental and economic benefits. Environmental engineering and management journal, 2018, 17(9):2103-2115.

17) Wan $K T$, Zhu H, Yuen T Y P , et al. Development of low drying shrinkage foamed concrete and hygro-mechanical finite element model for prefabricated building fasade applications. Construction \& Building Materials, 2018, 165(MAR.20):939-957.

18) Wesz J G B , Formoso C $T$, Tzortzopoulos $P$. Planning and controlling design in engineered-to-order prefabricated building systems. Engineering Construction \& Architectural Management, 2018, 25(2):134-152.

19) Griffith R . Implementing Offsite Construction and Prefabricated Building Systems. Design Cost Data, 2018, 62(3):50-50.

20) Qianqian S . Design of Prefabricated Old-age Building Based on Modularization:A Case Study of Institutional Elderly Houses Design in Taigou Village,Xi'an City. Journal of Landscape Research, 2018, 10(05):87-90.

21) Zhang $\mathrm{K}$, Tong $\mathrm{S}$, Zhao J , et al. Control method of shaft and hole mating based on convolution neural network in assembly building prefabricated components. IOP Conference Series Materials ence and Engineering, 2018, 399(1):012061.

22) Tang Q, Liu $Z$, Chen $W$, et al. The Application of BIM in Small and Medium-sized Smart Substation-A Case Study of Prefabricated Building Design. IOP Conference Series Earth and Environmental ence, 2018, 186(5):012054.

23) Teng $\mathrm{Y}, \mathrm{Li} \mathrm{K}$, Pan $\mathrm{W}$, et al. Reducing building life cycle carbon emissions through prefabrication: Evidence from and gaps in empirical studies. Building and Environment, 2018, 132(MAR.):125-136.

24) Yuan $Z$, Sun C, Wang Y . Design for Manufacture and Assembly-oriented parametric design of prefabricated buildings. Automation in Construction, 2018, 88(APR.):13-22. 
25) Inma García-Pereira, Cristina Portalés, Jesús Gimeno, et al. A collaborative augmented reality annotation tool for the inspection of prefabricated buildings. Multimedia Tools and Applications, 2019, 79(4):1-19.

26) Ferdous $\mathrm{W}$, Bai $\mathrm{Y}$, Ngo $\mathrm{T} \mathrm{D}$, et al. New advancements, challenges and opportunities of multi-storey modular buildings-A state-of-the-art review. Engineering Structures, 2019, 183(MAR.15):883-893.

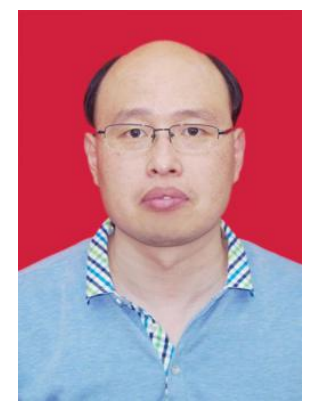

Xinhua Wu was born in Jining, Shandong。P.R. China, in 1978. He received the Master degree from Shandong University of Science and Technology, P.R. China. Now, he works in College of Resources, Shandong University of Science and Technology, His research interest include construction project management, Civil Engineering.

E-mail:skd992813@sdust.edu.cn

Figure:

Fig.1. Comparison of inventory turnover times of the two methods

Fig.2 Comparison of warehouse occupancy of two methods in construction process

Fig. 3 The ratio of surplus useless materials to total purchased materials in the two methods in the construction process

Fig.4 Comparison of material scrap rate of two methods in construction process 
Figures

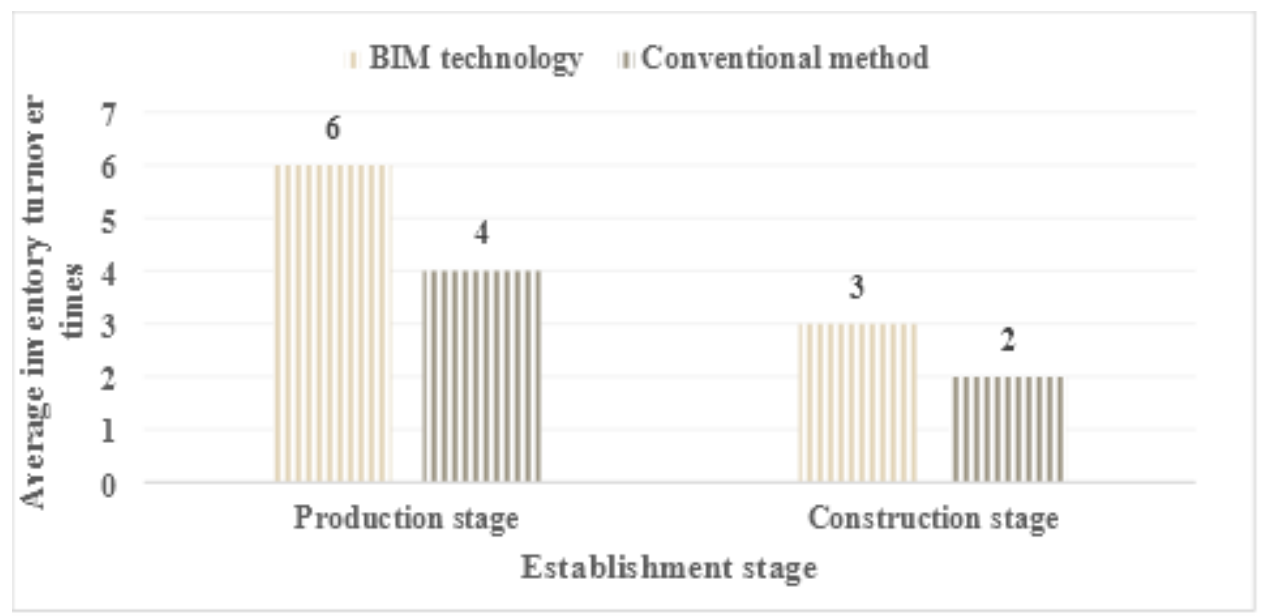

Figure 1

Comparison of inventory turnover times of the two methods

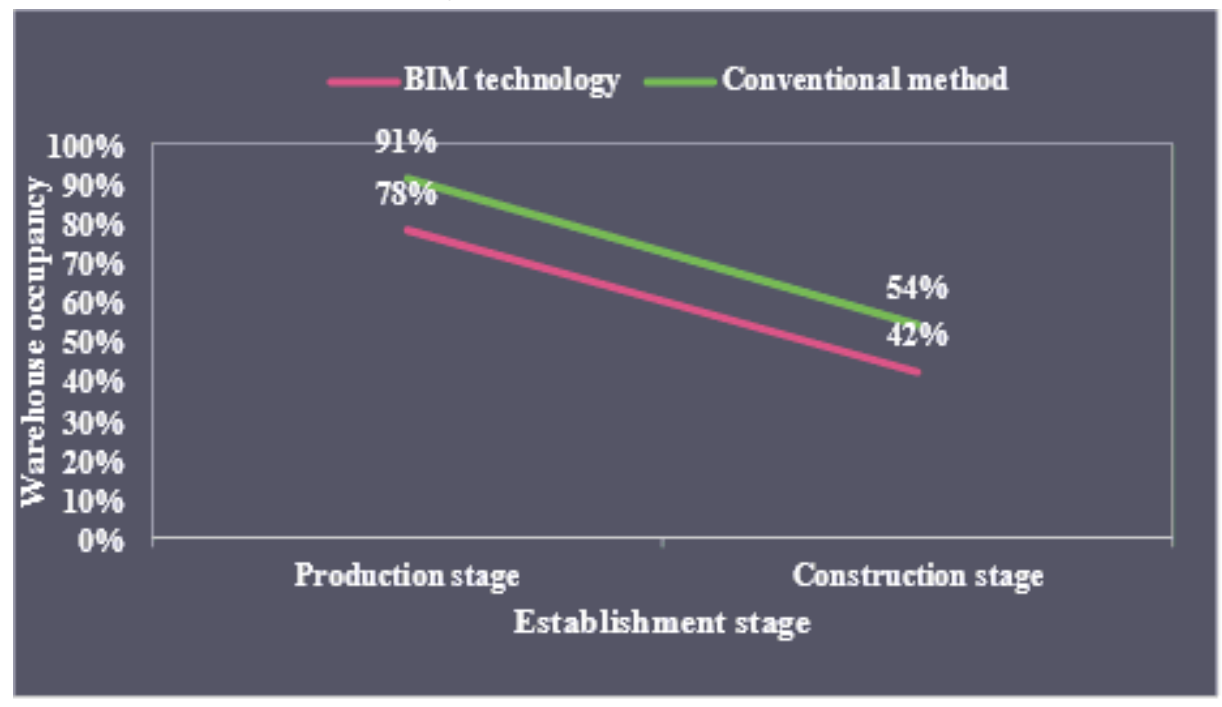

Figure 2

Comparison of warehouse occupancy of two methods in construction process 


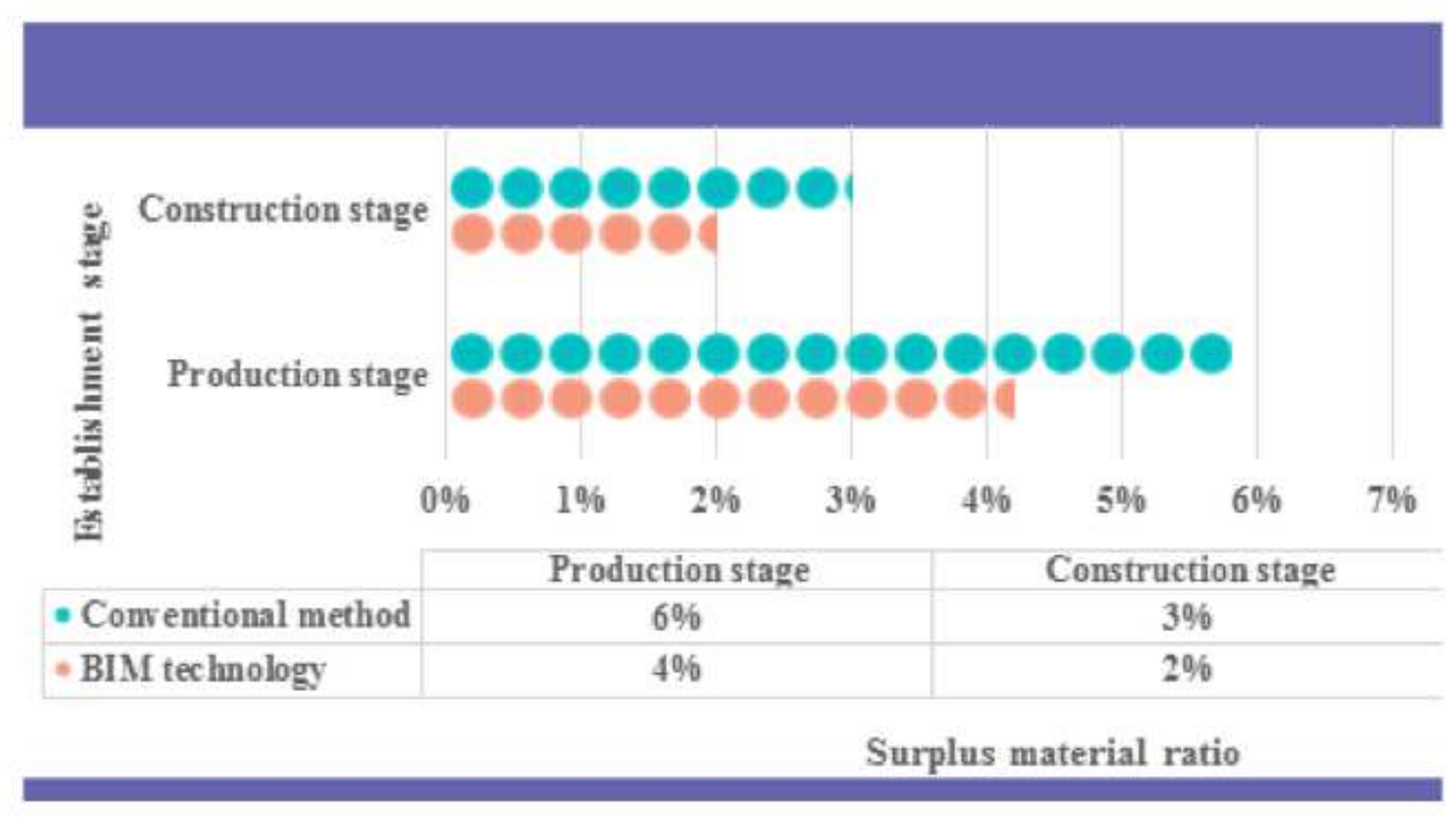

\section{Figure 3}

The ratio of surplus useless materials to total purchased materials in the two methods in the construction process

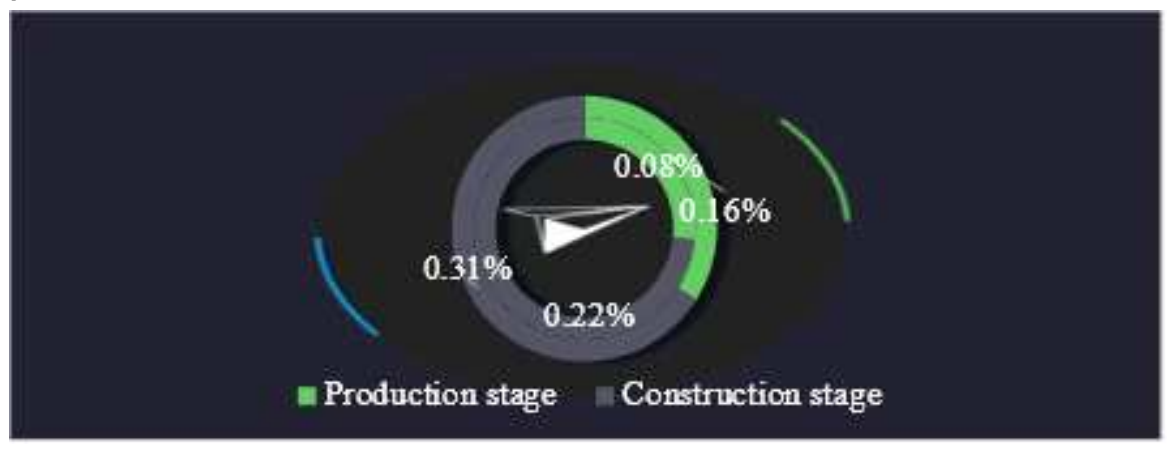

\section{Figure 4}

Comparison of material scrap rate of two methods in construction process 